\title{
FIBRINOLYTIC OR NOT: CASE SERIES OF STEMI AND DEADLY HEMORRHAGIC STROKE
}

\author{
Sidhi Laksono Purwowiyoto ${ }^{1^{*}}$, Steven Philip Surya ${ }^{2}$ \\ ${ }^{1}$ Fakultas Kedokteran, Universitas Muhammadiyah Prof. DR. Hamka, Indonesia \\ ${ }^{2}$ Rumah Sakit TK IV Cijantung Kesdam Jaya, Indonesia \\ *Correspondence email : sidhilaksono@uhamka.ac.id
}

\begin{abstract}
Cardiovascular diseases (CVD) like myocardial infraction (MI) is still becoming the leading cause of morbidity and mortality and major problem in our healthcare system. Nowadays, revolution in high-tech medical treatment alongside with well-trained staff could decrease adverse event in ST elevation myocardial infarction (STEMI) patient. However, in developing country like Indonesia, those still become a challenge. Fibrinolytic therapy is still common practice even though primary percutaneous coronary intervention (PPCI) preferred. Intracranial bleeding is one of the most unfavorable effect after fibrinolytic therapy. Clinical should aware with clinical deterioration. Here we present case series of deadly intracranial haemorrhage in STEMI patient after fibrinolytic therapy.
\end{abstract}

Keywords: Fibrinolytic: Intracranial Haemorrhagic; STEMI

\section{INTRODUCTION}

The mortality rate caused by cardiovascular diseases are increasing. In Indonesia there is significantly rising of cardiovascular mortality's number from 5\% in 1975 to $30 \%$ in $2004 .{ }^{1}$ One of the highest concerns for mortality indicate among cardiologist is Acute Myocardial Infarction (AMI). ${ }^{2}$ AMI patient with ST-elevation myocardial infarct (STEMI) needed to undergo reperfusion therapy immediately. Primary Percutaneous Coronary Intervention (PPCI) is the preferred reperfusion in patient with STEMI within 12 hours of symptoms onset, however this procedure is still difficult due lack of skilled support staff, geographic and structural differences in medical system like in Indonesia. ${ }^{1-3}$ Data from Jakarta Acute Coronary Syndrome (JAC) Registry data based from $2008-$ 2009 shows 654 acute STEMI patient who were admitted to the National Cardiovascular Center Harapan Kita (NCCHK), Jakarta, Indonesia only $29 \%$ patients undergo PPCI. ${ }^{1}$ Pharmacotherapy, using fibrinolytic therapy especially in early after

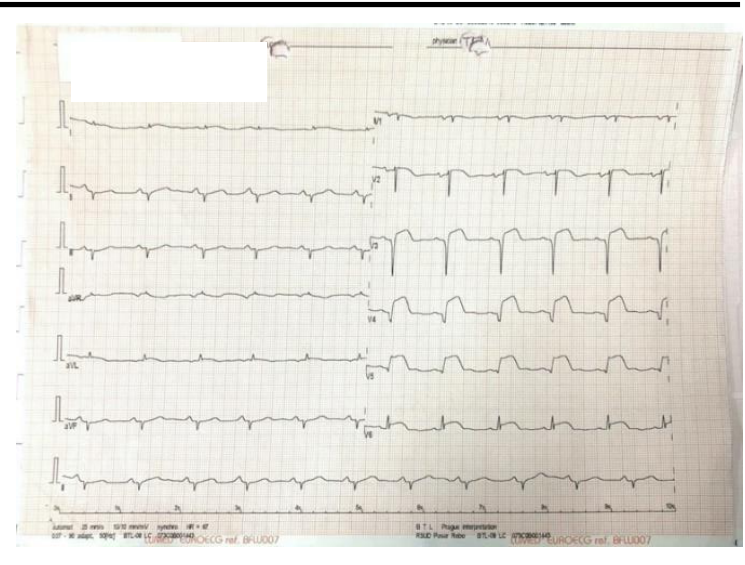

Figure 1. ECG Examination 20-08-2019, 05:32 AM (pre-fibrinolytic)

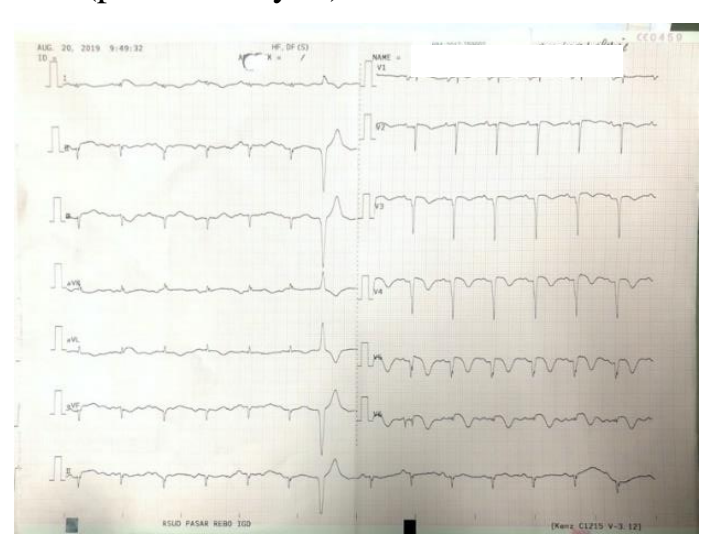

Figure 2. ECG Examination 20-08-2019, 09.49 AM (post-fibrinolytic)

onset of the symptoms offers a reasonable therapeutic option and has yielded satisfactory 
clinical result. $^{2}$ Fibrinolytic therapy plays an important role in the management of Acute Myocardial Infarction (AMI) to minimize tissue damage and boost survival rates. However, it has a significant risk of bleeding complications, including hemorrhagic stroke. ${ }^{4,5}$

\section{CASE 1}

A 65-year-old woman presented to RSUD Pasar Rebo emergency room (ER) because of migrated chest pain from left chest to the left arm for 6 hours. The chest pain was not worsened with rest, she complained of nausea and had a vomit one time. She had a history of controlled hypertension. Physical exam in ER revealed blood pressure (BP) 140/90 $\mathrm{mmHg}$, heart rate (HR) $64 \mathrm{bpm}$, respiratory rate 20 times per minute and body temperature $36.4^{\circ} \mathrm{C}$. A blood test revealed an increase of SGOT and troponin I and a decrease of urea blood. Electrocardiography showed sinus tachycardia with ST-segment elevation in V2 - V6 (Figure 1). Based on examination, there is no contraindication for fibrinolytic therapy. Streptokinase was administrated. After 60 minutes, the chest pain was disappeared and no complained, successful fibrinolytic was achieved (Figure 1 dan 2). Although the patient had paresthesia for 5 minutes during the procedure and patient transferred to the ward.

Eight hours later, the left hemiparesis still persists. Dynamic ST-T changes, bigeminy PVC and tachycardia was found (Figure 3-5). CT scan was performed and showed hemorrhagic stroke. After all of the antithrombotic and anticoagulant medication were discontinued, 19 hours and 30 minutes later, the patient had a loss of consciousness and the resuscitation was not performed due to requested Do Not Resuscitate (DNR). The patient died after 30 minutes (Figure 6).

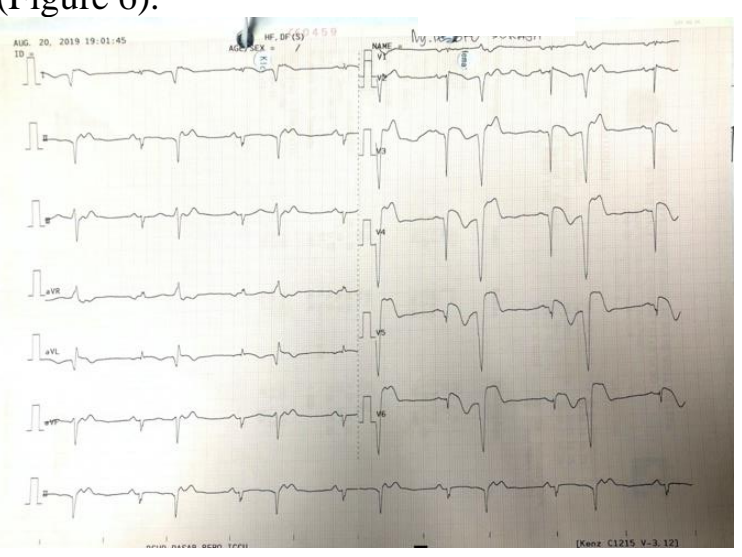

Figure 3. ECG Examination 20-08-2019, $07.01 \mathrm{PM}$

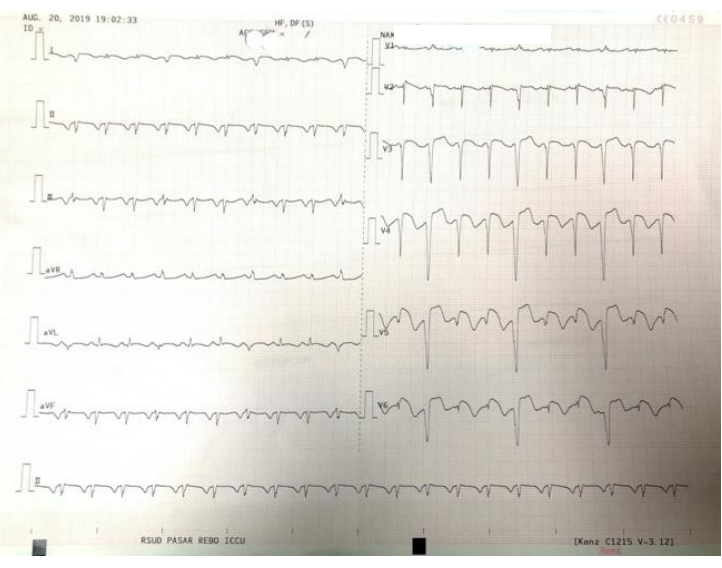

Figure 4. ECG Examination 20-08-2019, 07.02 PM

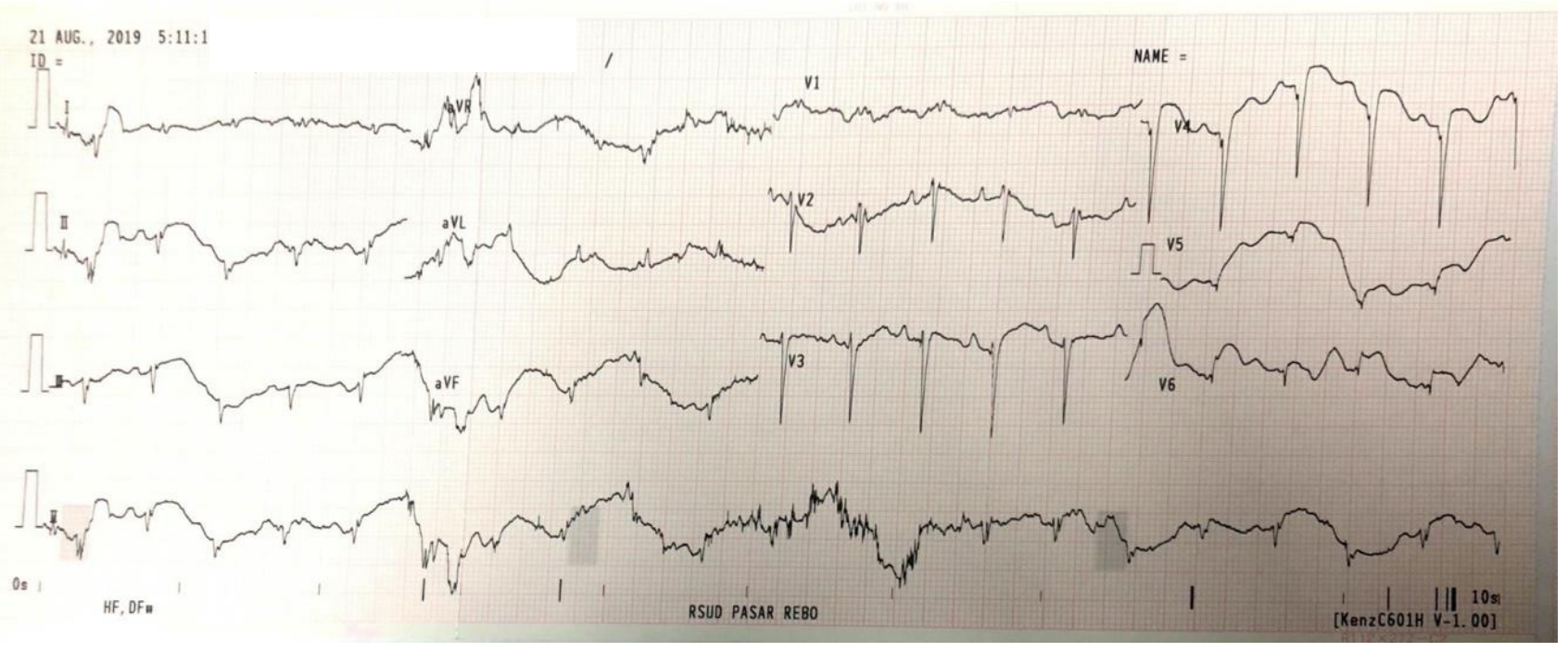

Figure 5. ECG Examination 21-08-2019, 05.11 AM 


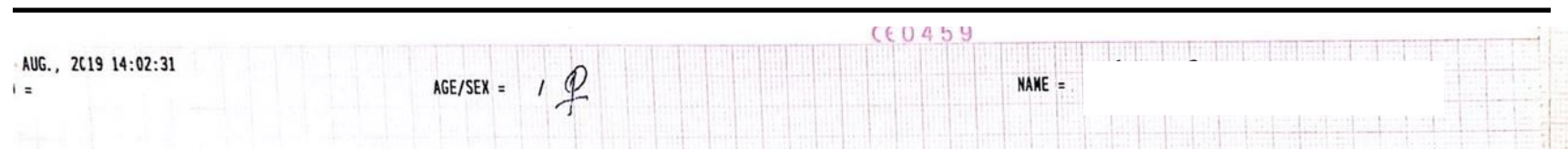

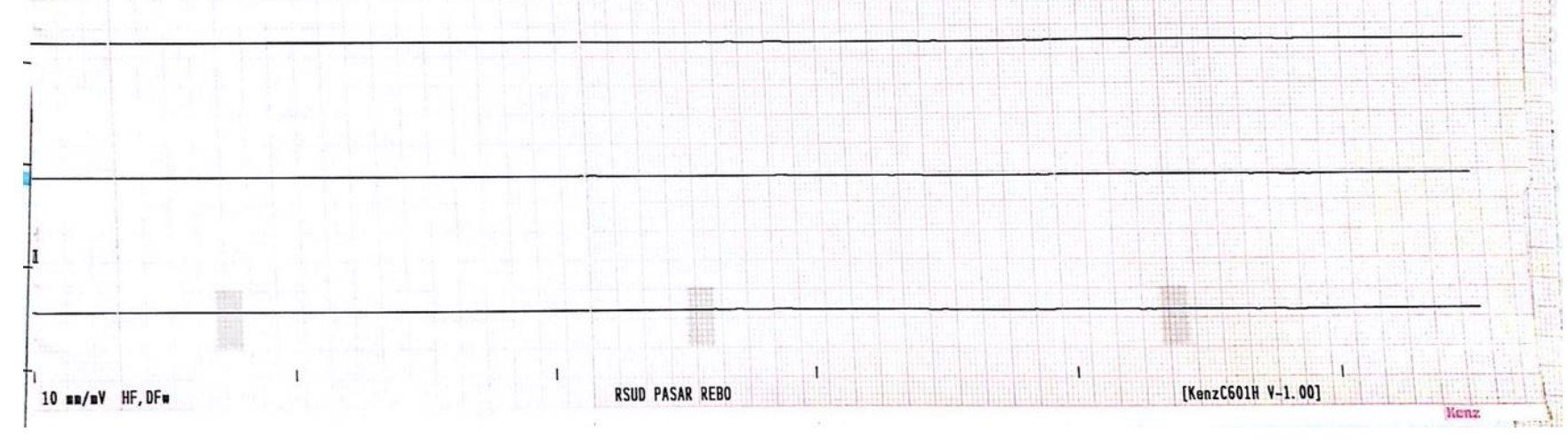

Figure 6. ECG Examination 21-08-2019, 02.02 PM

\section{CASE 2}

A 57-year-old, underweight woman presented to the ER with a 7-hour history of left sided chest pain, the pain described as tightness sensation in the chest, radiating up into her left shoulder and back. She had a history of uncontrolled hypertension and untreated left sided breast cancer. There is no history of diabetes mellitus and stroke. On examination, blood pressure was 148/92 $\mathrm{mmHg}$, pulse $70 \mathrm{bpm}$, and normal respiratory rate. The rest of the clinical examination was unremarkable. Twelve leads ECG showed sinus rhythm with ST elevation in leads V5V9 (Figure 7).

Acute coronary syndrome (posterolateral STelevation MI) was diagnosed and have no contraindication for fibrinolytic therapy. The patient administered with fibrinolytic (Streptokinase). Following fibrinolytic, the chest pain was completely subsided and her ST-elevation resolved (Figure 8).

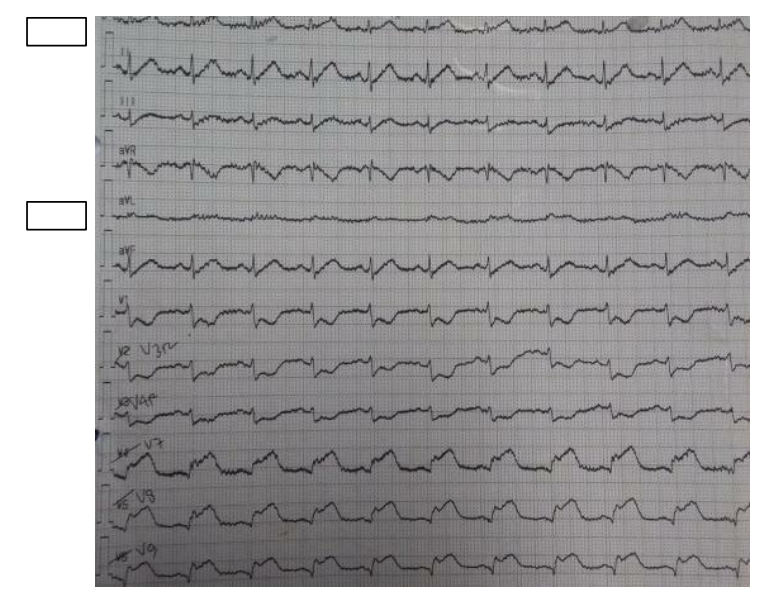

Figure 7. Initial ECG Examination

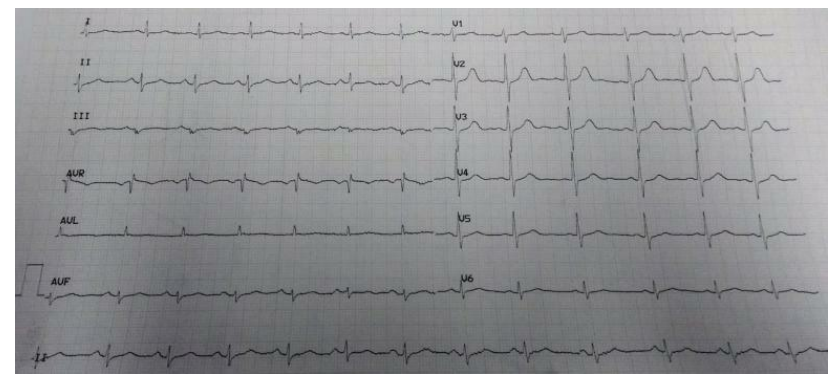

Figure 8. Post Fibrinolytic ECG Examination

She remained haemodynamically stable until 17 hours post fibrinolytic therapy when the patient experienced a sudden loss of unconsciousness. A brain CT was performed and showed intracranial haemorrhage (Figure 9). She was referred to the neurosurgeon who advised conservative management. Heparin, aspirin, and clopidogrel were discontinued.

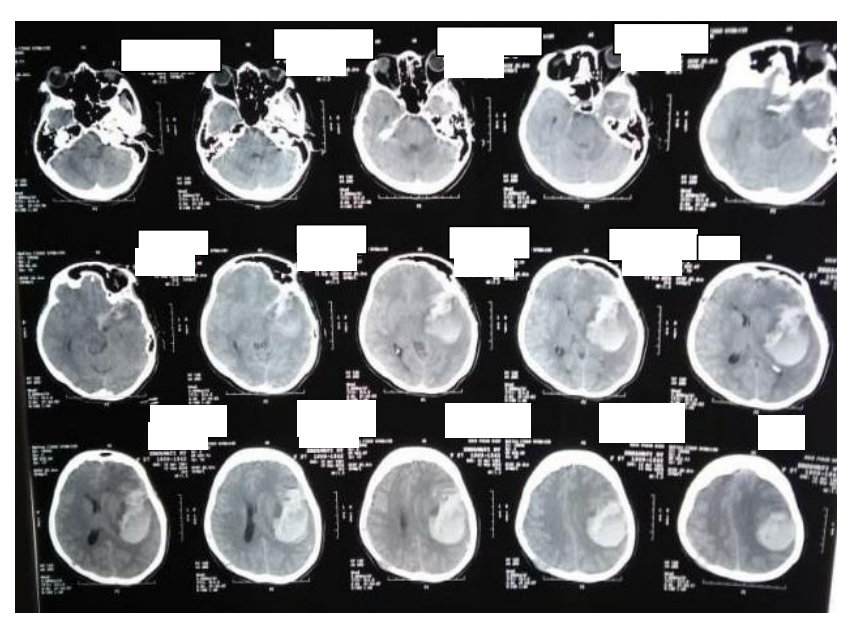

Figure 9. Brain CT 


\section{DISCUSSION}

Cardiovascular disease is one of the most common causes of morbidity and mortality in women in the developed countries. ${ }^{6}$ The Framingham Heart Study also shows women aged 44-64 years old has 8-9 times greater incidence of Myocardial Infarction (MI). ${ }^{7}$ As presented in our case series, both patients are woman with age 65 years old and 57 years old, respectively. Thrombolytic therapy for STEMI patient still common, even though PCI is preferred. A systematic study with total sample size 404,556 patient shows in STEMI patient regarding treatment, $71.2 \%$ received thrombolytics. ${ }^{4}$ In our case series, STEMI patient treated with pharmacological intervention, fibrinolytic therapy, seem reasonable.

The most serious complications of fibrinolytic therapy are death, re-infraction (AMI), and major bleeding (MB). The most MB that may be fatal in half to two-third of patients is haemorrhagic stroke. $^{5,8}$ Intracranial haemorrhage should be suspected in any patient who develops sudden neurological deterioration, a decline in the level of consciousness, new headache, nausea and vomiting or sudden rise in blood pressure (BP) after fibrinolytic therapy. Any symptoms which previously mention should alert the clinician and brain CT should be done to rule this out. The first 24 hours is the most common time to happened, the patient should be monitored closely. ${ }^{8}$ Similar with our patient, neurological deficit happened in both patients within 24 hours after thrombolytic therapy. We also performed brain CT on both patient and intracranial haemorrhage was found.

There are four factors that identified as independent predictors of intracranial haemorrhage; age over 65 years, bodyweight below $70 \mathrm{~kg}$, hypertension on hospital admission, and administration of alteplase. ${ }^{9}$ Hypertension is known to be a major risk factor for CVD. Study had found that the increase of SBP and DBP were associated with impaired fibrinolytic potensial. ${ }^{10}$ In these cases, both patients had a history of hypertension, but one patient had controlled hypertension and used antihypertension medication routinely. Although antihypertensive treatment does reduce the risk of CVD, the results are usually not commensurate to what would be predicted. ${ }^{11}$ This discrepancy may be caused by contributing factors, such as a prothrombic state, which is related to blood pressure level but is not corrected with antihypertensive treatment. Study had found that increased blood pressure is associated with decreased fibrinolytic potential and increased plasma viscosity supports the presence of a prothrombic state in hypertension. ${ }^{10}$

\section{CONCLUSION}

Haemorrhagic stroke is one of the most serious and fatal complication during the first 24 $\mathrm{h}$ of fibrinolytic therapy. Clinician should follow up patient clinical status and be aware with red flag symptoms after fibrinolytic therapy. There are several contributed factors, hypertension is one of the major risk factors. In this case, patient with controlled hypertension had a haemorrhagic stroke after fibrinolytic treatment, it can be caused by several factors such as a prothrombic state, which is related to blood pressure level but is not corrected with antihypertensive treatment.

\section{REFERENCES}

1. Dharma S, Juzar DA, Firdaus I, Soerianata S, Wardeh AJ, Jukema JW. Acute myocardial infraction system of care in the third word. Neth Heart J. 2012;20(6)2549.

2. Danchin N. Systems of care for st-segment elevation myocardial infraction: impact of different models on clinical outcomes. JACC Cardiovasc Interv. 2009;2(10):9018.

3. Ibanez B, James S, Agewall S, Antunes MJ, Bucciareli-Ducci C, Bueno $\mathrm{H}$, et al. 2017 ESC guidelines for the management of acute myocardial infraction in patients presenting with st-segment elevation: the task force for the management of acute myocardial infraction in patients presenting with ST-segment elevation of the European Society of Cardiology (ESC). Eur Heart J. 2018;39(2):119-77.

4. Nascimento BR, de Sousa MR, Demarqui FN, Ribeiro ALP. Risk and benefits of thrombolytic, antiplatelet, and anticoagulant therapies for st segment elevation myocardial infraction: systematic review. Int Sch Res Notices. 2014;2014:ID416253.

5. Bundhun PK, Janoo G, Chen MH. Bleeding events associated with fibrinolytic therapy and primary percutaneous coronary intervention in patient with STEMI. Medicine (Baltimore). 2016;95(23):e3877.

6. Bairey-Merz CN, Shaw LJ, Reis SE, Bittner V, Kelsey SF, Olson M, et al. Insight from the NHLBI-sponsored 
Women's Ischemia Syndrome Evaluation (WISE) study: part II: gender differences in presentation, diagnosis, and outcome with regard to gender-based pathophysiology of atherosclerosis and macrovascular and microvascular coronary disease. J Am Coll Cardiol. 2006;47(3 suppl):S21-9.

7. Mahmood SS, LevyD, Vasan RS, Wang TJ. The Framingham Heart Study and the epidemiology of cardiovascular diseases: a historical perspective. Lancet. 2014;383(9921):999-1008.

8. Ali SM, Rajani AR, Baslaib FA. Intracranial haemorrhage 4 days after receiving thrombolytic therapy in a young woman with myocardial infarction. BMJ Case Rep. 2013;2013:bcr2013009816.

9. Simoons ML, Maggioni AP, Knattereud G, et al. Individual risk assessment for intracranial haemorrhage during thrombolytic therapy. Lancet. 1993;342(8886-8887):1523-1528.

10. Poli KA, Tofler GH, Larson MG et al. Association of blood pressure with fibrinolytic potential in the Framingham Offspring Population. Circulation. 2000;101(3):264-269

11. MacMahon S, Peto R, Cutler J, Collins R, Sorlie P, Neaton J, Abbott R, Godwin J, Dyer A, Stamler J. Blood pressure, stroke and coronary heart disease, II: short-term reductions in blood pressure: overview of randomized drug trials in their epidemiological context. Lancet. 1990;335:827-838. 